\title{
PROCESSING OF POROUS SILICON CARBIDE COMPOSITE REINFORCED BY HIGH STRENGTH CARBON FIBERS
}

\author{
M. T. Elmestekawi \\ Department of Mechanical Engineering, \\ Higher Technological Institute, \\ 10th of Ramadan City, Egypt
}

\author{
Osama A. Hamed \\ Department of Production Eng. \&Mech. \\ Design, Faculty of Engineering, \\ Minoufiya University, Shebin El-Kom, Egypt.
}

\begin{abstract}
The use of porous matrices to enable damage tolerance in ceramic composites has emerged as a new paradigm in high performance materials. This paradigm obviates the need for fiber coatings for the purpose of crack deflection, thereby providing opportunities for lower cost MFG relative to that of conventional coated-fiber systems. Thus, the $\mathrm{C} / \mathrm{SiC}$-material shows a fiber-dominated behavior due to high fiber strength and matrix porosity. The characteristics and mechanical properties of this C/SiC are highlighted. The discussion deals with the particular mechanical characteristics of porous-matrix materials relating to similar materials investigated hitherto.

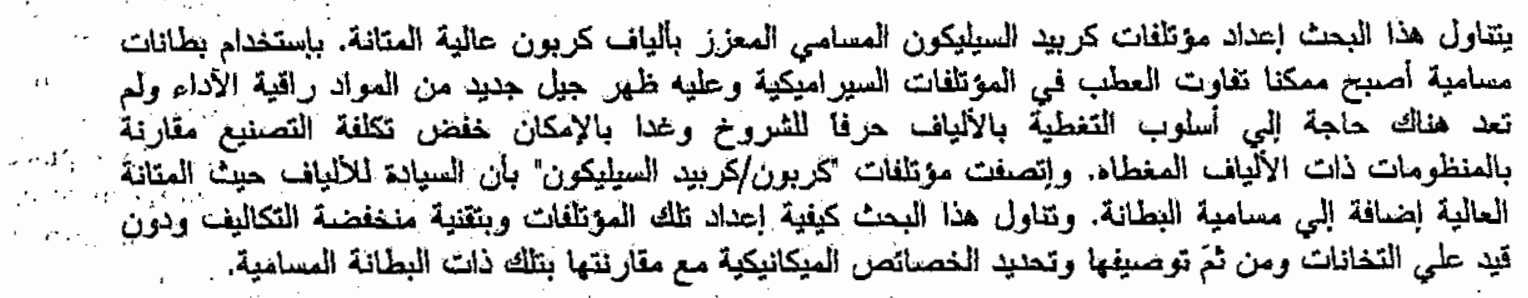

Keywords: Ceramic matrix composites (CMC), Porosity, Toughness, $\mathrm{SiC}, \mathrm{C} / \mathrm{SiC}$.

\section{INTRODUCTION}

In the field of high temperature applications, the use of ceramics is promising due to their constant strength up to high temperatures and their corrosion resistance. However, their brittle damage behavior impedes their broad industrial use. The implementation of fiber technology overcomes the poor damage tolerance of ceramic materials by fiber reinforcement (ceramic matrix composites- CMCs) [1-3]. Due to the high thermal stability of carbon, research on carbon fiber-reinforced carbon has been conducted for aerospace applications since the $1970 \mathrm{~s}$. In order to avoid this material's poor resistance to oxidizing atmosphere at higher temperatures, further development to carbon-fiber-reinforced silicon carbide $(\mathrm{C} / \mathrm{SiC})$ followed. Fiber reinforcement increases the fracture toughness of ceramic materials. Failure of the resulting ceramic matrix composites (CMC) is a process of crack propagation and crack branching, crack bridging by the fibers, and finally fiber failure in the opened crack. In order to utilize the strength of the individual fibers and to obtain damage-tolerant fracture behavior, fibet-matrix debonding and therefore a fracture of the fibers one by one is necessary. Thus, the structure of the matrix material, as well as the fiber-matrix interaction, strongly influences the mechanical properties of CMCs and must therefore be controlled by the processing technique [4-6]. Carbon-fiber-reinforced carbon $(C / C)$ is one of the first representatives of CMCs, which have been under development since the 1960 s $[2,7]$. Two main processing techniques have been established for the production of $\mathrm{C} / \mathrm{C}$ materials. In the case of chemical vapor infiltration (CVI), a fiber fabric perform is infiltrated with a gaseous precursor, so that carbon is subsequently deposited on the fibers. This process leads to a highperformance but expensive material as a result of long processing times $[2,8]$. Using the liquid phase infiltration (LPI) technique, the fibers are infiltrated by an organic material, which is subsequently cured and converted into carbon (carbonization). Thermosetting (resins) as well as thermoplastic (pitch) precursors can be used, which cause glassy carbon and graphitic structures to form during thermal treatment [2]. Cracks formed, due to shrinkage of the precursor, can be infiltrated again, followed by a further thermal treatment. This reinfiltration step causes the less demanding process 
to become more difficult and expensive. Furthermore, fiber-matrix adhesion must be lowered, using fiber coatings, in order to achieve non-brittle failure behavior due to fiber-matrix debonding [9]. According to the analysis of He and Hutchinson [9], debonding (i.e. crack-deflecting interface) also occurs in the case of strong fiber-matrix adhesion when a matrix material of low stiffness is used. This can be achieved, for example, by using a highly porous matrix material, which has hitherto been shown mainly for CMCs consisting of oxide materials [10-13]. An attractive option is the inclusion of silicon carbide $(\mathrm{SiC})$ particles in the matrix of $\mathrm{C} / \mathrm{C}$ materials in order to improve the wear resistance and mechanical strength. In this paper, a new material is presented, whereby $\mathrm{SiC}$ particles are homogeneously inserted into the carbon matrix material. This material is produced using a modified LPI method, where the matrix precursor is initially filled with fine-grained $\mathrm{SiC}$ particles. The resulting matrix material consists of homogeneously distributed glassy carbon, silicon carbide particles and small pores. Due to the porous matrix structure and the resulting low stiffness of the matrix material, the use of fiber coatings to reduce fiber-matrix bonding is not necessary. The processing method for this $\mathrm{C} / \mathrm{C}$-SiC material is outlined. The material is characterized according to its microstructure, pore size distribution and mechanical properties (bending test, as well as single-edge notch beam (SENB) test).

\section{MATERIALS AND EXPERIMENTAL WORK}

\subsection{Processing}

A carbon fiber bundle (HTA 5131, Tenax Fibers GmbH \& Co. KG), phenolic resín (K790, Bakelite $\mathrm{AG}$ ), hexamethylenetetramine (Merck $\mathrm{KGaA}$ ) as hardener, and $\mathrm{SiC}$ powder with a particle size of $\mathrm{d}_{10}=$ $0.2 \mu \mathrm{m}, \mathrm{d}_{50}=0.7 \mu \mathrm{m}$ and $\mathrm{d}_{90}=1.5 \mu \mathrm{m}$ (UF-15, H.C. Starck) were used as raw materials. A matrix suspension was prepared by adding $\mathrm{SiC}$ powder to a solution of phenolic resin and hexamethylenetetramine ( $9 \mathrm{wt.} \%$ ) in isopropanol. The amount of $\mathrm{SiC}$ was calculated so that the resulting matrix consisted of 60 vol. \% SiC and 40 vol. \% C. The fiber bundle was impregnated by the matrix suspension, as shown in Figure 1. The resulting prepregs were cut after drying and stacked in a mould to produce unidirectional or $0^{\circ} / 90^{\circ}$ laminated material. Winding techniques were used for the preparation of composites, in order to achieve a homogeneous distribution of the SiC particles in the matrix material and around the carbon fibers. The resin was cured under a pressure of $20 \mathrm{MPa}$ at $190^{\circ} \mathrm{C}$ to achieve a dense carbon-fiber-reinforced plastic (CFRP) with SiC particles Figure (1).

During carbonization at up to $1000^{\circ} \mathrm{C}$ in a flowing argon atmosphere, the cured polymer was transformed into glassy carbon. A final temperature treatment in vacuum conditions was performed at $1450^{\circ} \mathrm{C}$, similar to the reaction treatment for the reactive silicon filler. Different furnaces were used, so that the samples could cool down and handled in air between the temperature treatments. $\mathrm{A} \mathrm{C} / \mathrm{C}$ with homogeneously distributed $\mathrm{SiC}$ particles was obtained (C/C-SiC, Figure 1. During the transformation of the resin into carbon, a shrinkage of more than $50 \%$ occurred. Since the composite was dimensionally stable, due to fiber-reinforcement, it experienced almost no shrinkage. Thus, a porosity of approx. $20 \%$ was formed. As the $\mathrm{SiC}$ particles were added at the beginning, no further infiltration steps were necessary. Thus, the processing technique does not limit wall thickness. For comparison, some composites were investigated without being subjected to the final temperature treatment. The transformation of the resin into carbon was in principle completed after treatment at up to $1000^{\circ} \mathrm{C}$, but a further rearrangement of the carbon structure could occur by heating it up to $1450^{\circ} \mathrm{C}$. Other composites were prepared by adding silicon ( $\mathrm{Si}$ ) powder instead of silicon carbide $(\mathrm{SiC})$ powder of the same particle size and quantity to the matrix suspension as described above. During temperature treatment at $1450^{\circ} \mathrm{C}$ (above the melting point of silicon), a reaction of silicon and carbon took place and silicon carbide was formed. The matrix material was thus completely converted into silicon carbide with a higher porosity (more than $30 \%$ ) than was found for the SiC filler. Pores and silicon carbide material were homogeneously distributed.

\subsection{Characterization}

To investigate the microstructure and homogeneity, polished cross sections of the $\mathrm{C} / \mathrm{C}-\mathrm{SiC}$ were examined using an optical microscope PMG3 from Olympus. The pore structure was analyzed by mercury porosimetry (Pascal 140 and 440 from Fisons Instruments), as was the adsorption of nitrogen using BET (Sorptomatic 1990 from Thermo Quest Italia S.p.A.). The mechanical properties were analyzed using bending tests. A three-point bending test was performed with a bearing distance of $100 \mathrm{~mm}$ to reduce shear stresses. An automated, electromechanical universal testing machine (Zwick 1387 from Zwick, Germany) was used at a constant crosshead speed of $0.5 \mathrm{~mm} / \mathrm{min}$. The specimens had a width of $10 \mathrm{~mm}$ and a thickness of approx. $3 \mathrm{~mm}$ (six layers). Specimens of different types of reinforcements (unidirectional and $0^{\circ} / 90^{\circ}$-laminated), as well as those treated at different temperatures $\left(1000\right.$ and $\left.1450^{\circ} \mathrm{C}\right)$ were tested. At least 12 specimens were measured in each case for statistical significance. The values of stress and strain were derived from linear bending theory. In order to determine the fracture toughness and fracture behavior, single-edge notch beam (SENB) tests were 
performed. These features are best examined in experiments with a stable crack extension. Thus, a four-point bending test with bearing distances of 60 and $20 \mathrm{~mm}$ was used. Specimens with a thickness of approx. $5 \mathrm{~mm}$ (12 layers) and a starting notch with a length between one-third and one-half of the specimen width were prepared using a diamond saw blade. For testing, the specimens were oriented edgewise so that a crack spread out in the direction of the starting notch Figure (2). This test cannot be applied for unidirectional fiber reinforcement because of delaminating. Thus, $0^{\circ} / 90^{\circ}$ laminates (ten specimens) of the $\mathrm{C} / \mathrm{C}-\mathrm{SiC}$ material were tested after heat treatment at $1450^{\circ} \mathrm{C}$. The results were then compared with those of $\mathrm{C} / \mathrm{SiC}$ material, where the silicon carbide matrix was formed by a reaction of silicon and carbon, as described above. During the test, the bridging of the crack by the fibers is the dominant factor and the effect of reinforcement could then be investigated. Therefore, the fracture surfaces and the load-displacement curves were analyzed. A scanning electron microscope (Ultra55 from Zeiss) was used to investigate the fracture surface. The load was normalized in terms of the formal stress intensity factor $K_{\mathrm{l} \text {, form }}=\sigma \mathrm{V}_{\mathrm{a}_{0}} \mathrm{Y}$, where $\mathrm{a}_{0}$ is the starting notch length and $Y$ is a function for geometrical correction. It was shown, and verified by model calculations, that the fracture resistance of different materials can be compared using this method [14, 15]. The maximum value is interpreted as the formal fracture toughness, which is independent of the different specimen dimensions and starting notch lengths. For a variety of different materials, it was shown that the formal fracture toughness, as well as the shape of the curve, differed significantly [15]. As the formal fracture toughness refers to the starting notch length, it gives a lower bound for the effective fracture toughness, which is based on the actual crack length.

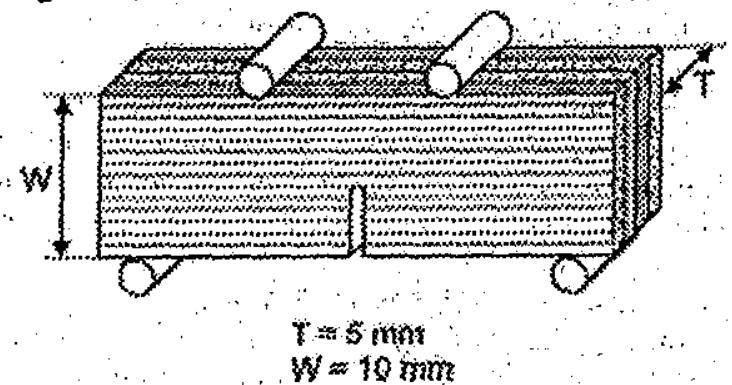

Fig. 2 Schematic of four-point configuration for SENB tést

\section{RESULTS AND DISCUSSION}

\subsection{Microstructure}

The microstructure of the resulting material $\left(0 \% 90^{\circ}-\right.$ laminated) is shown in Figure (3). The different layers can be easily distinguished. In the layers where cross sections of the fibers are visible, segmentation cracks can be seen Figure (3a). These cracks resulted from resin shrinkage. This is a typical phenomenon in CMC materials. The fibers are straightly oriented in each layer. They are also homogenously distributed within each fiber bundle Figure ( $3 b)$. The matrix materials, silicon carbide and glassy carbon, are located homogeneously around each fiber. A few larger pores can also be seen. In Figure (4), the pore size distributions of the $0 \% / 90$-laminated $\mathrm{C} / \mathrm{C}-\mathrm{SiC}$ after temperature treatment at 1000 and $1450^{\circ} \mathrm{C}$ are shown. Approx. $8 \%$ in the pore radii range of $0.02-$ $100 \mu \mathrm{m}$ was detected with a broad distribution. These pores can be attributed to the segmentation cracks, which are of different thicknesses, as can be seen in Fig. (3a), and also to pores inside the fiber bundles (see Fig. 3b) caused by small inhomogeneities. Further pores (more than 10\%) were almost of the sarme size (pore radii of $0.01-0.02 \mu \mathrm{m}$ ). These small pores were formed within the matrix material, between the glassy carbon and the $\mathrm{SiC}$ particles in homogeneous distribution. The number of pores with radii larger than $0.02 \mu \mathrm{m}$ did not significantly increase with an increasing heat treatment temperature. The total porosity measured by mercury porosimetry, which could be detected down to a pore radius of $2 \mathrm{~nm}$, increased after temperature treatment at $1450^{\circ} \mathrm{C}$. However, the slope of the curve for $1000^{\circ} \mathrm{C}$ in the range of small pore radii $(<0.01 \mu \mathrm{m}$, Figure 3) suggests that saturation was not reached. Thus, a certain number of smaller pores presumably remained below the detection limit, which increased during heat treatment at $1450^{\circ} \mathrm{C}$. These were verified by geometrical calculations, as well as by BET measurements (see Table 1). The geometrical porosity was determined using the theoretical density of the components, the composition and the measured dimensions of a composite. After heat treatiment at $1000^{\circ} \mathrm{C}$, the results for porosity, as well as for specific surface measured by mercury intrusion were significantly lower than the results measured geometrically and by BET. After "temperature treatment at $1450^{\circ} \mathrm{C}$, the results converged. Temperature treatment at $1450^{\circ} \mathrm{C}$ thus caused an increase- in the number of the smallest pores, especially for those with radii less than 2 nim up to a value of $20 \mathrm{~nm}$, and therefore led to a reduced specific surface area. This can be attributed on the one hand to an influence of oxygen on the surface properties after temperature treatment at $1000^{\circ} \mathrm{C}$ when the composites were removed from the fumace at room temperature (a cracking could be heard). It is well known, that $\mathrm{SiC}$ forms a layer of silicon oxide at the surface. Furthermore, a large BET surface can result from oxygen linked at the surface. During reheating, a slight oxidation or removal of the oxide layer can result in an increase in the pore radii (an additional mass loss of $3 \%$ was detected). On the other hand, a certain rearrangement of the carbon material (for example stress-induced graphitization, 
even if this process is not pronounced at temperatures below $1600^{\circ} \mathrm{C}$ ) is assumed. Verification has to be done by further investigations (surface chemistry, increase in carbon density).

\subsection{Mechanical Properties}

The results of the three-point bending tests are summarized in Table 2. Since the fiber volume content was almost equal for all compared materials, Young's modulus and the bending strength were directly comparable. Due to the low matrix stiffness, Young's modulus for the composites was dominated by the fibers. Thus, it was almost the same for both unidirectional reinforced materials. Half the value was reached for the $0^{\circ} / 90^{\circ}$ laminated material, when half of the fibers were positioned in the load direction. The bending strength can also be determined by the fibers in the load direction. Once more, the bending strength of $0^{\circ} / 90^{\circ}$-laminated material was half the value of that for unidirectional reinforced $\mathrm{C} / \mathrm{C}-\mathrm{SiC}$. The bending strength of $\mathrm{C} / \mathrm{C}$ $\mathrm{SiC}$ after temperature treatment at $1000^{\circ} \mathrm{C}$ was directly comparable to $\mathrm{C} / \mathrm{C}-\mathrm{Si}$ determined in previous investigations.
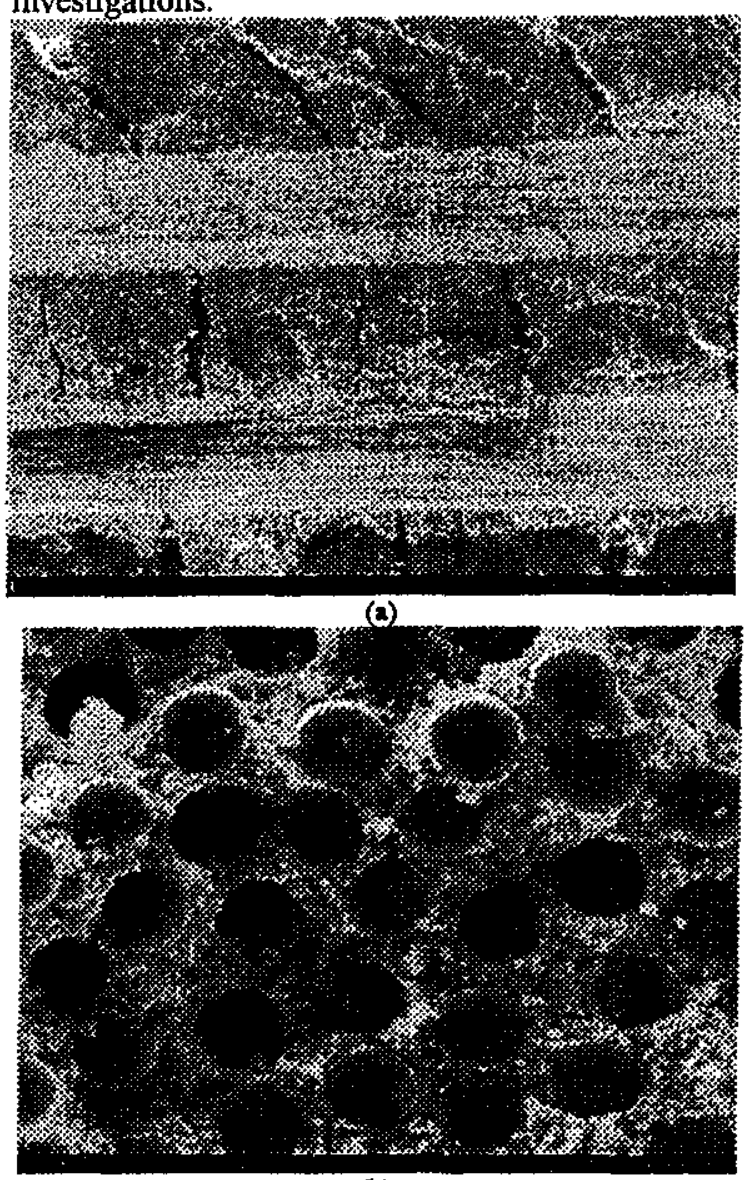

(b)

Fig. 3 Optical micrographs of a polished cross section of $0^{\circ} / 90^{\circ}$-laminated $\mathrm{C} / \mathrm{C}-\mathrm{SiC}$ :

(a) Overview with layers and segmentation cracks,

(b) Homogeneous distribution of matrix within a fiber bundle.
Table (1) $0^{\circ} / 90^{\circ}$-Laminated C/C-SiC: total porosity and specific surface, comparison of Measurement methods

\begin{tabular}{lcccc}
\hline & \multicolumn{3}{c}{ Porosity (\%) } & \multicolumn{3}{c}{ Specific surface $\left(\mathrm{m}^{2} / \mathrm{g}\right)$} \\
& Mercury & Geometrical & Mercury & BET \\
\hline After $1000^{\circ} \mathrm{C}$ & 19.0 & 21.0 & 18 & 95 \\
After $1450^{\circ} \mathrm{C}$ & 21.4 & 21.5 & 13 & 26 \\
\hline
\end{tabular}

The only difference after this temperature treatment step is the type of filler particles. Consequently, no significant difference in the bending strength was found $(690=100 \mathrm{MPa}$ for $\mathrm{C} / \mathrm{C}-\mathrm{Si}$ and $620 \pm 50 \mathrm{MPa}$ for $\mathrm{C} / \mathrm{C}-\mathrm{SiC}$ ). These values are relatively high (comparable composites without filler particles: up to

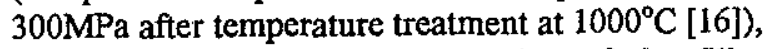
which allows a strengthening effect of the filler particles, as well as an influence of the homogeneously distributed pores to be assumed. After heat treatment at $1450^{\circ} \mathrm{C}$, the bending strength of the C/C-SiC material increased.

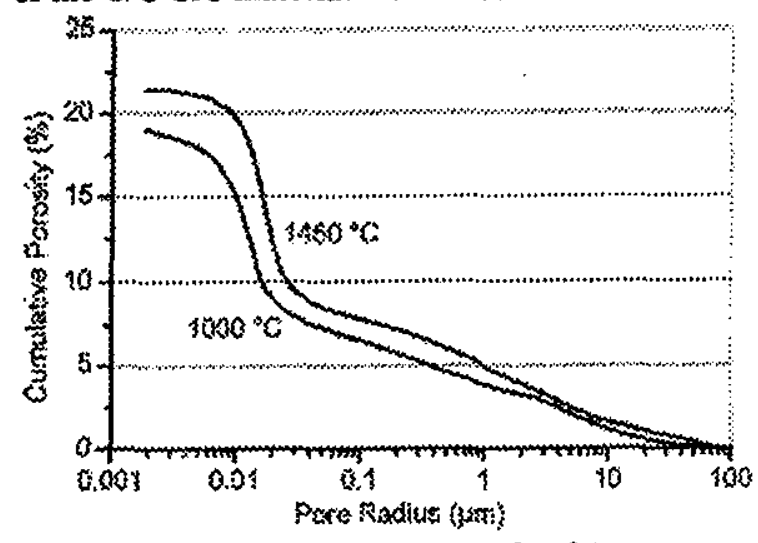

Fig. 4 Pore size distributions of $0^{\circ} / 90^{\circ}$-laminated $\mathrm{C} / \mathrm{C}-\mathrm{SiC}$, treated at 1000 and $1450^{\circ} \mathrm{C}$

A further amount of pores with a radius of about 0.02 $\mu \mathrm{m}$, within the matrix material, positively influenced the mechanical properties. Some nearly dense areas had disappeared for the benefit of porous areas. The advantage of the porous matrix material to improve the mechanical properties can be particularly utilized, as the porosity consists of small pores, which are homogeneously distributed in the whole composite. Studies on the influence of further reinfiltration steps to reduce the matrix porosity $[17,18]$ show also that inhomogeneously distributed porous and dense areas result in a brittle damage behavior. A crack starting in a dense and brittle area continues straight through the whole cross section due to a high energy release and causes premature failure of the component. Where silicon is used as filler material, a reaction of silicon and carbon cause a porous (approx. $0.1 \mu \mathrm{m}$ in pore radii) silicon carbide matrix to form during temperature treatment at $1450^{\circ} \mathrm{C}$. The bending strength of unidirectional reinforced material decreases in this case to a value of $360 \pm 45 \mathrm{MPa}$ (comparison: $690 \pm 100 \mathrm{MPa}$ after $1000^{\circ} \mathrm{C}$ ). A certain fiber attack was detected. Furthermore, the pores 
were larger $(0.1 \mu \mathrm{m}$ compared with $0.02 \mu \mathrm{m})$ and the filler particles were not preserved as they were in the case of the developed $\mathrm{C} / \mathrm{C}-\mathrm{SiC}$ material (770 $\pm 50 \mathrm{MPa}$ after temperature treatment at $1450^{\circ} \mathrm{C}$ ). The fracture behavior and formal fracture toughness (Table 2) were determined using SENB tests. A representative, normalized load-displacement curve of the $\mathrm{C} / \mathrm{C}-\mathrm{SiC}$ material with $\mathrm{SiC}$ filler is shown in Figure (5). A curve of the material with porous $\mathrm{SiC}$ matrix obtained by reaction of carbon and silicon (C/SiC) is included for comparison. The stiffiness of these materials, as well as the specimen dimensions were nearly equal, which meant that the displacement could also be compared. The $\mathrm{C} / \mathrm{C}-\mathrm{SiC}$ material showed an early deviation from linearity before reaching the maximum value for the formal stress intensity factor (i.e. the formal fracture toughness).

Table (2) Young's modulus, bending strength and formal fracture toughness of bidirectional and unidirectional reinforced $\mathrm{C} / \mathrm{C}-\mathrm{SiC}$.

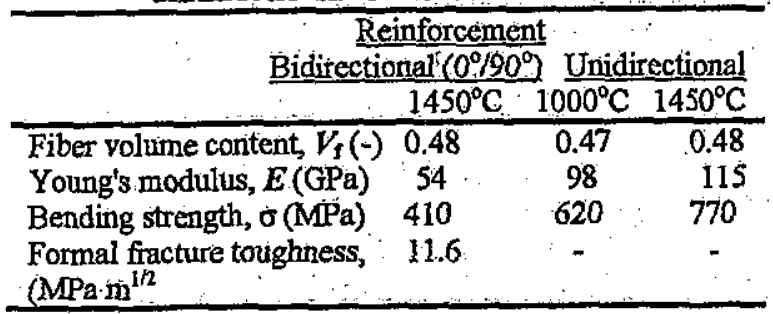

This indicates a damage-tolerant fracture behavior, which was also verified by micrographs of the fracture surface Figure (6). The fracture surface was jagged. There was obvious subsequent breaking of whole fiber bundles "(between the segmentation cracks). This was also detected in the stepped curve. These fiber bundles also had jagged surfaces with fiber pull-out and did not break in one plane. In some areas, long fibers that were pulled out were observed, which once more pointed out the damage tolerance of the developed material. The mechanism of crack bridging was clearly more effective for the $\mathrm{C} / \mathrm{C}-\mathrm{SiC}$ material than for material with a reaction formed silicon carbide matrix (C/SiC). A significantly higher maximum load and displacement was reached Figure 5. Furthermore, the fracture surface clearly showed more single fiber pull-out (see [13] for comparison), As well as interpreting the load-displacement curves and fracture surfaces, the formal fracture toughness can also be evaluated quantitatively. The material with a SiC filler (C/C-SiC) also had a significantly higher formal fracture toughiness $\left(11.6 \pm 0.8 \mathrm{MPa} \mathrm{m}{ }^{1 / 2}\right)$ compared to thie $\mathrm{C} / \mathrm{SiC}$ material with a reactionformed silicon carbide inatrix $\left(7.7 \pm 0.5 \mathrm{MPa} \mathrm{m} \mathrm{m}^{1 / 2}\right)$. An influence of the following three effects is probable: in the material with $\mathrm{SiC}$ filler, no fiber attack due to the reaction of silicon with carbon fibers can take place, so that the fiber strength was preserved. The pore size in the case of the material with a SiC filler was smaller (pore radius of $0.02 \mu \mathrm{m}$ compared to $0.2 \mu \mathrm{m}$ ) which possibly influenced the function of the weak matrix material. The SiC filler also led to further improvement through particle reinforcement. This increase in formal fracture toughness was remarkable, as $60-70 \%$ of the values of high-performance CMC materials produced by the liquid polymer infiltration (LPI) technique and by chemical vapor infiltration (CVI), which are in the order of $17-21 \mathrm{MPa} \mathrm{m}^{1 / 2}$, were reached $[15,19]$. No optimization of the $\mathrm{SiC}$ content has been done hitherto.

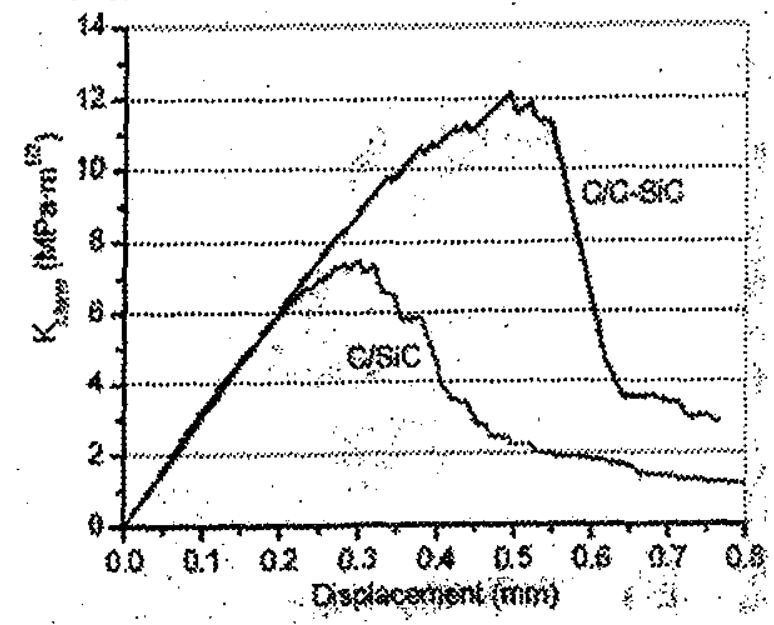

Fig. 5 Plot of formal stress intensity factor vs. displacement for $0^{\circ} / 90^{\circ}$ laminates with $\mathrm{SiC}$ filler (C/C-SiC) and Si filler (C/SiC) after temperature treatment at $1450 \circ \mathrm{C}$

If the amount of $\mathrm{SiC}$ particles is too high, inhomogeneities can occur. Furthermore, the amount of resin decreases, which also causes the porosity to decrease and results in a reduced bonding of $\mathrm{SiC}$ particles. A low amount of $\mathrm{SiC}$, in contrast, reduces the possibilities of particle reinforcement. A higher. amount of resin leads to a higher porosity, but also to. larger pores and larger regions of pure glassy carbon, which could reduce the crack branching effects.

\section{CONCLUSTON}

A novel processing method for the production of a carbon fiber-reinforced carbon composite, filled with $\mathrm{SiC}_{\mathrm{C}}$ particles $(\mathrm{C} / \mathrm{C}-\mathrm{SiC})$, has been demonstrated. The investigations led to the following conclusions:

1. A low-cost processing technique without limitations in wall thickness and the necessity of fiber coatings was developed.

2. A laminated structure with typical segmentation cracks and homogeneous distribution of fibers. and matrix material inside the fiber bundles was obtained. The $\mathrm{SiC}$ filler particles were homogeneously distributed in the single fiber: bundles.

3. A porous matrix material with a low stiffness was attained. A narrow distribution of the pore radii $(0.02 \mu \mathrm{m})$ within the fiber bundles was detected. The total porosity value was approx. $20 \%$. 

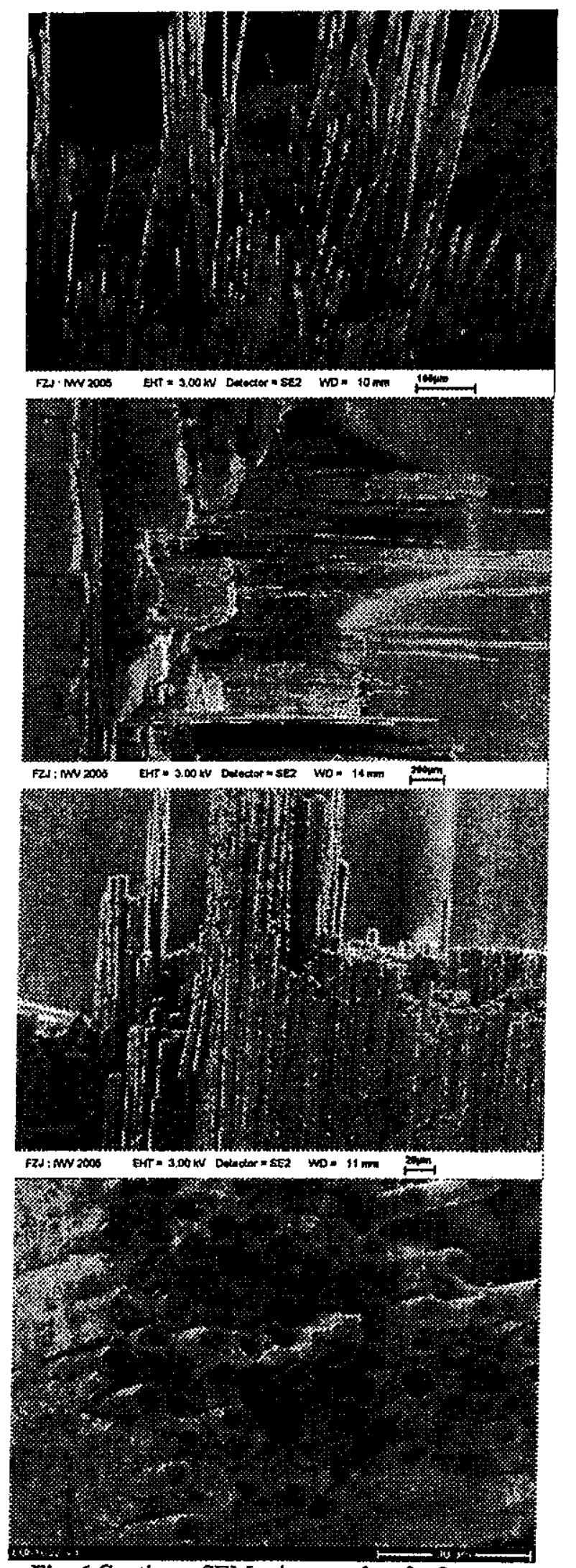

Fig. 6 Continue, SEM micrographs of a fracture surface after SENB test of $0^{\circ} / 90^{\circ}$-laminated C/C-SiC
4. Comparable high values for bending strength and formal fracture toughness were evaluated. This was attributed to three effects: no fiber attack by silicon, small pore size with homogeneous distribution of the pores and strengthening caused by $\mathrm{SiC}$ particles. The mechanism of crack bridging by fibers worked well and a non-brittle fracture behavior was obtained.

5. The formal fracture toughness of the developed low-cost $\mathrm{C} / \mathrm{C}-\mathrm{SiC}$ material of $12 \mathrm{MPa}$ $\mathrm{m}^{1 / 2}$ converged towards the values for high performance $\mathrm{CMC}$ materials of 17 up to $21 \mathrm{MPa}$ $\mathrm{m}^{1 / 2}$.

\section{ACKNOWLEDGEMENT}

The authors are grateful to the staff of IWVI Institute, Research Center Juelich, Germany, for their valuable assistance and discussion along the duration of the present work.

\section{REFERENCES}

[1] A.R. Bunsell, in: R. Warren (Ed.), CeramicMatrix Composites, Chapman \& Hall, New York, 1992, pp. 12-34.

[2] G. Savage, Carbon-Carbon Composites, Chapman \& Hall, London, 1993.

[3] F.F. Lange, C.G. Levi, F.W. Zok, in: R. Warren (Ed.), Carbon/Carbon, Cement, and Ceramic Matrix Composites in: A. Kelly, C. Zweben (Eds.), Comprehensive Composite Materials, vol. 4, Elsevier, Amsterdam, 2000, pp. 427-448.

[4] A.G. Evans, F.W. Zok, J. Mater. Sci. 29 (1994) 3857-3869.

[5] A.G. Evans, D.B. Marshall, Acta Metall. 37 (1998) 2567-2583.

[6] G. Grathwohl, M. Kuntz, E. Pippel, J. Wolterdorf, Phys. Stat. Sol. (a) 146 (1994) 393-414.

[7] Th. Ngai, in: S.M. Lee (Ed.), International Encyclopedia of Composites, vol, 1, VCH Publishers, New York, 1990, pp. 158-187.

[8] L.E. McAllister, W.L. Lachmann, in: A. Kelly, S.T. Mileiko (Eds.), Handbook of Composites, vol. 4, North-Holland, 1983, pp. 109-175.

[9] M.Y. He, J.W. Hutchinson, Int. J. Solids Struct. 25 (1998) 1053-1067.

[10] F.F. Lange, W.C. Tu, A.G. Evans, Mater. Sci. Eng. A 195 (1995) 145-150.

[11] W.C. Tu, F.F. Lange, A.G. Evans, J. Am. Ceram. Soc. 79 (1996) 417-424.

[12] F.F. Lange, T.C. Radsick, M. Holmquist, in: W. Krenkel, R. Naslain, H. Schneider (Eds.), High Temperature Ceramic Matrix Composites, Wiley-VCH, Weinheim, 2001, pp. 587-599.

[13] Sauder, C., Lamon, J. and Pailler, R., Compos. Sci. Technol., 2002, 62, pp. 499-504. 
M.T. Elmestekcwi, Osama A. Hamed, "Processing of Porous Silicon Carbide Composite Reinforced by High ..."

[14] G. Rausch, M. Kuntz, G. Grathwohl, J. Am. Ceram. Soc. 83 (2000) 2762-2768.

[15] M. Kuntz, Risswiderstand keramischer Faserverbundwerkstoffe, $\mathrm{PhD}$ Thesis, University of Karlsribe, Karlsnuhe, Germany, 1995.

[16] R.M. Rocha, C.A.A. Cairo, M:L.A. Graca, Materials Science and Engineering A 437 (2006) 268-273
[17] G.J. Qi, C.R. Zhang, H.F. Hu, Journal of NonCrystalline Solids 352 (2006) 3794-3798.

[18] J. She, P. Mechnich, H. Schneider, M. Schmuecker, B. Kanka, Mater. Sci. Eng. A 325 (2002) 19-24.

[19] J.S. Kim, Y.S. Kwon, O.I. Lomovsky, M.A. Korchagin, V.I. Mali, D.V. Dudina, Materials Letters 60 (2006) 3723-3726 